\title{
Pensamentos e sentimentos sobre envelhecimento: um estudo das representações sociais em produtores rurais de Diamantino - MT
}

\author{
Thoughts and feelings about aging: a study of \\ social representations in rural producers in \\ Diamantino city, Mato Grosso, Brazil
}

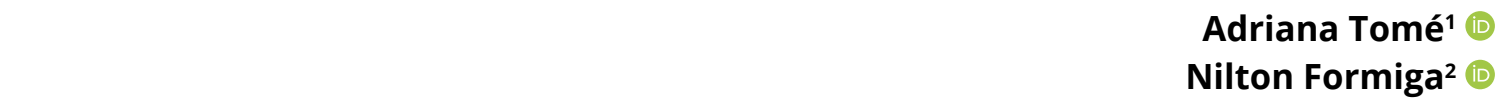

${ }^{1}$ Autora para correspondência. Universidade de Ciências Empresariais e Sociais (Buenos Aires). Argentina. adriana.tome@gmail.com universidade Potiguar (Natal). Rio Grande do Norte, Brasil. nsformiga@yahoo.com

RESUMO | INTRODUçÃo: O envelhecimento humano é um fenômeno mundial que pode ser analisado como um processo natural, contínuo, progressivo e irreversível, onde há alterações orgânicas, psicológicas e morfofuncionais. O processo de envelhecer é visto de forma diferenciada em cada cultura, podendo ser marcado por aspectos positivos e negativos. OBJETIVOS: O presente estudo objetivou analisar os pensamentos e sentimentos sobre envelhecimento para pequenos e grandes produtores rurais do município de Diamantino - MT. MÉTODOS: Participaram da pesquisa 28 produtores rurais do município de Diamantino - MT, do sexo masculino, e idade entre 65 e 87 anos; 64,3\% tem Ensino Fundamental Incompleto; 67,9\% é casado e moram com suas esposas, e/ou filhos e/ou netos. A respeito do recebimento sócio assistencial, 50\% recebem aposentadoria, 17,9\% recebem algum Benefício de Prestação Continuada (BPC) e 17,9\% não recebe aposentadoria e nem benefício. Os entrevistados foram divididos em dois grupos: o primeiro composto por produtores rurais cuja posse de propriedade(s) não ultrapassa 100 hectares classificado como pequeno produtor, e o segundo por produtores com propriedade(s) que totalizam mais de 100 hectares. Para a análise, utilizou-se a Teoria das Representações Sociais e o método de análise de conteúdo do discurso. RESULTADOS: Os sentimentos e pensamentos sobre enveIhecimento foram classificadas nas seguintes categorias emergentes do construto envelhecimento: Enfrentamento (46,42\%), Desespero $(21,42 \%)$, Integridade (14,28\%), Sujeição/Submissão (3,57\%), Agressão $(3,57 \%)$ e sem sentido $(10,71 \%)$, que são apresentadas neste artigo pela amostra geral, contendo as informações dos pequenos e grandes produtores. CONSIDERAÇõES FINAIS: Os pensamentos e sentimentos atribuídos ao envelhecimento estão relacionados ao bem-estar e qualidade de vida, e a capacidade funcional, nível socioeconômico, estado emocional, interação social, atividade intelectual, autocuidado, suporte familiar, estado de saúde, religiosidade, entre outros.

PALAVRAS-CHAVE: Envelhecimento. Enfrentamento. Respeito. Dominação-Subordinação.
ABSTRACT | INTRODUCTION: Human aging is a worldwide phenomenon that can be analyzed as a natural, continuous, progressive, and irreversible process, where there are organic, psychological, and morphofunctional changes. The aging process is seen differently in each culture and can be marked by positive and negative aspects. OBJECTIVES: This study aimed to analyze the thoughts and feelings about aging for small and large rural producers in the municipality of Diamantino - MT. METHODS: Participated in the research, 28 rural producers of Diamantino - MT, male and aged between 65 and 87 years old; $64.3 \%$ have incomplete Elementary Education; $67.9 \%$ are married and live with their wives, and/or children and/or grandchildren. Regarding the social assistance receipt, 50\% receive retirement, 17.9\% receive some Benefício de Prestação Continuada (BPC) and 17.9\% receive none. The interviewees were divided into two groups: the first composed of rural producers whose ownership of property (ies) does not exceed 100 hectares classified as a small producer, and the second by producers with property (ies) that total more than 100 hectares. For analysis, the Social Representations Theory and the Discourse Content Analysis method were used. RESULTS: The feelings and thoughts about aging were classified into the following categories emerging from the aging construct: Confrontation (46.42\%), Despair (21.42\%), Integrity (14.28\%), Subjection / Submission (3.57\%), Aggression (3.57\%) and senseless $(10.71 \%)$, presented in this article, show a general sample, containing the information of two small and large producers. CLOSING REMARKS: The thoughts and feelings attributed to aging are related to well-being and quality of life, and functional capacity, socioeconomic status, emotional state, social interaction, intellectual activity, self-care, family support, health status, religiosity, among others.

KEYWORDS: Aging. Coping. Respect. Dominance-Subordination. 


\section{Introdução}

Os dados divulgados pelo Instituto Brasileiro de Geografia e Estatística (IBGE, 2018), pela Organização Mundial da Saúde (OMS, 2015) e pela Organização das Nações Unidas - ONU (2014) mostram que a expectativa de vida da população brasileira vem crescendo cada dia mais, acarretando o aumento da população de terceira idade. Em 2000, quase 10 milhões de pessoas no Brasil tinham 65 anos ou mais, e até 2100 acredita-se que a população idosa brasileira será em torno de 70 milhoes (35\% da população geral) e a população com mais de 80 anos será de 30 milhões (15\% da população geral) (IBGE, 2018).

Isso tem se dado graças ao crescimento econômico, melhor nutrição, melhor controle de doenças infectocontagiosas, melhora no estilo de vida e alimentação, melhora nas instalações sanitárias, água mais pura, avanço da ciência, tecnologia e medicina, além do declínio na fertilidade (BNDES, 2017; Papalia \& Feldman, 2013).

Nos países em desenvolvimento, como é o caso do Brasil, o idoso é entendido como aquele com 60 anos ou mais. Para os teóricos contemporâneos da Psicologia do Envelhecimento, o desenvolvimento é transacional, dinâmico e contextualista, e assim o envelhecimento sofre influências ontogenéticas, biológicas e psicossociais (Neri, 2006).

Segundo Parente (2006), o envelhecimento humano é um processo de transformações orgânicas com reflexo nas estruturas físicas, cognitivas e na percepção subjetiva. O conceito de velhice é construído no transcorrer da existência humana, que não permite conceitos absolutos e universais, e a representação que se tem do envelhecimento na sociedade possibilita ações legítimas ao ser que envelhece (Neri, 2013).

O envelhecimento humano ocorre em três níveis: biológico, psicológico e social. O envelhecimento pode ser analisado como um processo natural, contínuo, progressivo e irreversível, onde há alterações orgânicas, psicológicas e morfofuncionais, que tornam o indivíduo menos capaz psicofisicamente, além de vulnerável às doenças e à síndrome da fragilidade (Monteleone et al., 2015).
As mudanças das funções orgânicas são manifestadas durante o envelhecimento e tendem a aumentar com o tempo, com um ritmo que varia não só de um órgão para outro, mas também entre idosos da mesma idade (Azevedo, 2015). Essas inúmeras alterações orgânicas e morfofuncionais são diferentes para cada idoso, pois dependem de condições sociais, culturais e econômicas que o indivíduo experimenta no decorrer de sua vida.

Na concepção de Azevedo (2015), o processo de envelhecimento é multifatorial e subjetivo, e por este motivo cada indivíduo envelhece de uma maneira diferenciada. As condições biológicas estão intimamente relacionadas à idade cronológica, onde há mudanças fisiológicas, anatômicas, bioquímicas e hormonais, acompanhadas da diminuição progressiva da eficiência das funções orgânicas do corpo humano (Azevedo, 2015; Monteleone et al., 2015).

As condições sociais, e com ela a forma que a sociedade percebe o sujeito que envelhece, variam de acordo com o momento histórico e cultural de cada sociedade. $O$ envelhecimento em seu aspecto social tem a ver com as normas e os valores sociais e culturais ao qual o idoso pertence, e com a criação de novos papéis sociais que poderão ser positivos ou negativos, pois estão interligados às questões econômicas e sociais (Freitas, 2017; Torres et al., 2015; Vilela, 2018).

Vasconcelos e Jager (2016, p. 180) pontuam que, com relação aos idosos no ambiente familiar, "pode não haver uma valorização e compartilhamento de seus valores, conhecimentos e significação de sua existência", e o sucesso do convívio familiar "depende muito da qualidade do relacionamento que existiu no passado e da habilidade de ambas as gerações de se comunicar de maneira plena e franca" (Papalia \& Feldman, 2013, p. 619).

As dificuldades de comunicação intrafamiliar podem dificultar o envolvimento dos idosos na rotina familiar, as trocas diárias, o estabelecimento de memórias e tradições familiares, dificultando a transmissão cultural de geração para geração. Já a coesão familiar, o convívio harmonioso e o apoio são benéficos à qualidade de vida do idoso, mas também favorecem a transmissão de informações, sentimentos, sensações, vivências e crenças (Papalia \& Feldman, 2013; Vasconcelos \& Jager, 2016). 
Com relação aos aspectos cognitivos, algumas habilidades podem declinar com o avanço da idade, como por exemplo, a velocidade de processamento mental, o raciocínio abstrato, deterioração da memória, atenção e concentração, o baixo nível de tolerância, a insegurança, a completa falta de ânimo e atenção, bem como o estreitamento da afetividade, no entanto, outras habilidades tendem a melhorar no decorrer da vida adulta (Parente, 2006; Sticca \& Pádua, 2016). A aceitação do indivíduo acerca de seu envelhecimento, questões de cunho psicológico que causam muitas vezes atitudes hostis por parte de muitos idosos, devem ser trabalhadas, pois são as principais causas de isolamento, sentimento de rejeição e depressão.

Ainda os fatores psicológicos devem ser considerados, analisados e até trabalhados (tratados) pela sociedade e pelo idoso. O envelhecimento psicológico é determinado pelas mudanças concretas do enveIhecimento biológico e também pelas normas e estereótipos sociais, apresentados como comportamentos abertos e/ou encobertos da pessoa em relação a si e aos outros, associados as mudanças de atitude e limitações, como insadaptações, readaptações e reajustamentos de repertórios comportamentais (Jesuíno et al., 2017). Sendo assim, as características funcionais encontram dificuldades na perda da independência, autonomia e aumento da necessidade de ajuda para desempenhar atividades diárias básicas destas pessoas.

Um levantamento das últimas investigações sobre o tema mostra que a velhice é uma fase da vida marcada por aspectos positivos, relacionados à experiência, sabedoria e aposentadoria (Torres et al., 2015), e também por vários estereótipos como a passividade, a improdutividade, degeneração orgânica e psíquica, além da desvinculação com o futuro (Jesuíno et al., 2017). Segundo Levy et al. (2002), os estereótipos sociais sobre os idosos são adquiridos ainda na infância e podem impactar na forma como os próprios sujeitos se percebem. Complementam ainda que, quanto mais positivas as percepções sobre o envelhecimento, maiores a manifestações sobre o desejo de viver.

Segundo Consenza e Malloy-Diniz (2013, p. 444), o preconceito etário é uma "barreira à implementação das mudanças necessárias e deve ser combatido, pois limita o acesso dos idosos aos serviços, à educação e ao trabalho e pode levar ao abuso, à negligência e ao abandono".

Com o processo de urbanização, houve mudança no contexto social e também nos espaços rurais, sendo a agricultura transformada em um ramo industrial. $O$ rural brasileiro (?) passou a ser relacionado principalmente à exportação com grande influência na economia brasileira (Muniz \& Souza, 2018). No entanto, ainda existem produtores com menores terras e com produções mais voltadas a subsistência, ou seja, a produção está voltada para a garantia de sobrevivência do agricultor, sua família e comunidade, mas que produzem também cerca de $70 \%$ dos alimentos que são consumidos pela população em geral (Santos \& Barbosa, 2019).

Além disso, o envelhecimento em contexto rural não se diferencia do contexto urbano, apesar de ser mais intenso devido à precariedade dos serviços rurais. Ocorre que nos espaços rurais brasileiros entre as décadas de 60 e 70, houve a modenização da agricultura que favoreceu os grandes proprietários e consequente descapitalização dos pequenos produtores. Atualmente, isso reflete no crescente êxodo rural pela população jovem, que migra das pequenas propriedades em busca e novas oportunidades e perspectivas de vida, deixando os produtores rurais idosos sem este tipo de suporte na execução das atividades rurais (Ferraz, Alves \& Ferreti, 2017). Desta forma, os espaços rurais brasileiros são habitados quase que exclusivamente por pessoas idosas (Ferraz et al., 2017).

Desta forma, busca-se analizar os pensamentos e sentimentos sobre envelhecimento para pequenos e grandes produtores rurais do município de Diamantino - MT. Para tal, a Teoria das Representações Sociais se faz adequada para este tipo de estudo, pois, os estudos realizados por meio das representações sociais, conforme Moscovici (1981), possibilita-nos a compreensão social por meio da cultura e sociedade na qual o sujeito está inserido, pois, indivíduo, grupo e sociedade são indissociáveis na apreensão do saber cotidiano, o que faz com que as representações sociais sejam constantemente alimentadas por conhecimentos originados na experiência cotidiana e também pelas reapropriações dos significados consolidados historicamente. 


\section{Método}

O presente estudo caracteriza-se por um estudo qualitativo, exploratório e descritivo, por meio da Teoria das Representações Sociais (Moscovici, 1981), e envolveu 28 produtores rurais do município de Diamantino - MT, divididos em dois grupos: o primeiro grupo foi composto por produtores rurais cuja posse de propriedade(s) não ultrapassa 100 hectares classificado como pequeno produtor, e o segundo grupo foi composto por produtores com propriedade(s) que totalizam mais de 100 hectares. A divisão de pequeno ou grande produtor se baseou na dimensão de um módulo fiscal para o município de Diamantino - MT (Lei nº.746/1979 - Brasil, 1979).

Como seleção dos sujeitos desta pesquisa, optou-se por serem do sexo masculino; ter entre 65 e 90 anos; trabalhar em atividades rurais; residir no município de Diamantino - MT; e concordar em participar do estudo e assinar o termo de consentimento livre e esclarecido;

Por ser um estudo desenvolvido no Brasil, foram adotados todos os procedimentos obedecendo os Critérios da Ética em Pesquisa com Seres Humanos conforme Resolução no. 510/2016 do Conselho Nacional de Saúde. Assim, o projeto foi submetido ao Comitê de Ética e Pesquisa apresentando todos os termos de acordo com as exigências da resolução 510/2016 e a Norma Operacional 001/2013 do CNSConselho Nacional de Saúde e aprovado sob CAAE 84295317.2.0000.5166.

O questionário foi aplicado aos idosos de forma individual, de acordo com a disponibilidade do tempo e espaço físico em suas residências. Estes entrevistados foram contatados por meio do Sindicato Rural de Diamantino (SRD). Cada idoso que participou da pesquisa foi solicitado a indicar outros participantes, dentro do método bola-de-neve; estes, foram convidados a participar de forma voluntária, anônima e privada para responder as questões apresentadas. Nenhum deles foi obrigado participar da pesquisa, podendo desistir da a qualquer momento.
Aos participantes que concordaram em participar da pesquisa, por vontade própria, solicitou-se a assinatura do termo de Consentimento Livre e Esclarecido (TCLE), onde se informou o objetivo do estudo, bem como os riscos e benefícios e, em seguida, o próximo passo do estudo, que foi responder o questionário.

Após a coleta de dados, foi feita a transcrição integral das gravações. Os dados do Questionário Sócio Demográfico foram analisados por meio de estatística descritiva. A partir do material transcrito, e, tendo em vista a grande quantidade de respostas obtidas, preliminarmente submeteu-as a uma análise de semântica do conteúdo, por meio da Análise de Conteúdo do Discurso (Bardin, 2009) possibilitando, uma primeira análise léxica e lógico-estrutural de seus conteúdos, pois, segundo Bardin (2009, p. 14), “por detrás do discurso aparente, geralmente simbólico e polissêmico, esconde-se um sendo que convém desvendar".

Após transição das entrevistas, o material coletado foi analisado, codificado, classificado e categorizado, conforme o que preconiza Bardin (2009). Este processo facitou o refinamento e evitou as possíveis ambiguidades durante a categorização, e permitem a descrição das características pertinentes ao conteúdo de cada categoria, baseados em aspectos no discurso dos sujeitos e sua relação com o material teórico disponível sobre a temática.

\section{Resultado e discussão}

A respeito da idade, $64,28 \%$ tinham idade entre 65 e 74 anos, $25 \%$ entre 75 e 84 anos e $10,72 \%$ com 85 anos ou mais. Sobre o nível de escolaridade, $71,43 \%$ não tem escolaridade formal, ou estudou até o ensino fundamental incompleto, sendo que somente $28,57 \%$ tem escolaridade de ensino médio e ensino superior.

Do grupo entrevistado, $67,85 \%$ é casado, $14,28 \%$ é separado ou divorciado, $14,28 \%$ é viúvo e $3.57 \%$ é solteiro. A menor quantidade de filhos foi 2 e maior foi 12 , sendo que $42,86 \%$ possuía entre 2 e 3 filhos; $35,71 \%$ tem entre 4 e 6 filhos, e; $21,3 \%$ entre 7 e 12 filhos. 
A respeito dos netos, a quantidade variou entre 0 e 14 netos. $50 \%$ dos idosos têm entre 0 e 5 netos; $32,14 \%$ têm entre 6 e 10 netos e, $10,71 \%$ tem entre 11 e 14 netos. 7,14\% não souberam quantificar os netos.

A respeito das relações familiares, $10,71 \%$ relata viver sozinho, $28,57 \%$ vive somente com a esposa; $7,14 \%$ vive somente com os filhos; $28,57 \%$ residem com esposa e filhos, $10,71 \%$ reside com esposa e netos; $3,57 \%$ reside com esposa, filhos e netos, 5,37\% reside com os genitores, 3,57\% reside com ex esposa e 3,57\% reside com outras pessoas que não são familiares.

A respeito da relação com a produção rural, 64,28\% afirma ter contato com o trabalho rural desde criança, 3,57\% teve início na adolescência e $32,14 \%$ na vida adulta. A respeito do tamanho da propriedade, $7,14 \%$ dos pequenos produtores tem entre 1 e 10 hectares, $25 \%$ entre 2 e 30 hectares, 17,85\% entre 31 e 40 hectares e 7,14\% com propriedade que seja superior a 40, porém inferior a 100 hectares; 7,14\% dos grandes produtores tem entre 100 e 500 hectares, $14,28 \%$ entre 501 e 1000 hectares, 17,86\% entre 10001 e 3000 hectares e 3,57\% com mais de 3001 hectares. Desta forma, percebe-se que mesmo que os entrevistados tenham tido contato com o trabalho rural desde criança $(64,28 \%)$, somente 35,71\% possuem propriedades acima de 501 hectares.

A respeito da situação de recebimento de aposentadoria, benefício e/ou pensão, tem-se que: 17,86\% não recebe qualquer tipo de aposentadoria e benefício, 50\% recebe aposentadoria, 17,86\% recebe benefício, 3,57\% recebe pensão por falecimento, 3,57\% recebe aposentadoria por invalidez, e 7,14\% recebe aposentadoria e pensão.

A respeito dos pensamentos e sentimentos atribuídos ao envelhecimento, foram classificadas as seguintes categorias emergentes do construto envelhecimento: Integridade, Enfrentamento, Desespero, Sujeição/Submissão e Agressão, conforme Quadro abaixo:

Quadro 1. Categorias emergentes na questão "O que significa envelhecimento para você" na amostra total (pequenos e grandes produtores)

\begin{tabular}{|l|c|c|c|}
\hline & Nt & NPp & NGp \\
\hline Enfrentamento & 46,42 & 37,5 & 58,33 \\
\hline Desespero & 21,42 & 18,75 & 25 \\
\hline Integridade & 14,28 & 18,75 & 8,33 \\
\hline Sem sentido & 10,71 & 12,5 & 8,33 \\
\hline Sujeição/Submissão & 3,57 & 6,25 & 0 \\
\hline Agressão & 3,57 & 6,25 & 0 \\
\hline
\end{tabular}

Fonte: construção dos autores. Notas: Nt: Número total; NPp: Número Pequenos Produtores; NGp: Número Grandes Produres

Em termos de percentuais, foi contemplada Integridade (14,28\%) e Enfrentamento (46,42\%), Desespero (21,42\%), Sujeição/Submissão (3,57\%) e Agressão (3,57\%); chama-se atenção nestes resultados que, é preciso destacar a existência de $10,71 \%$ do discurso apresentou falta de sentido (por exemplo, considerou-se quando o conteúdo apresentado na resposta, não condiz com o que é perguntado e/ou diverge completamente da proposta hipotizada da categoria).

Esta questão, analisada pelas amostras de pequenos e grandes produtores separadamente, possibilita observar-se os seguintes percentuais para os pequenos produtores: Integridade (18,75\%) e Enfrentamento (37,5\%), Desespero (18,75\%), Sujeição/Submissão (6,25\%), Agressão (6,25\%) e sem sentido (12,5\%). Já para os grandes produtores, observaram-se os seguintes percentuais para cada categoria: Integridade (8,33\%), Enfrentamento (58,33\%), Desespero (25\%) e sem sentido (8,33\%). Para os grandes produtores, não houve nos discursos analisados as categorias Sujeição/Submissão e Agressão. 
Segundo Levinson (1978), com o envelhecimento ocorrem algumas redefinições de papéis familiares e profissionais e o reestabelecimento de novas metas para o final da vida. A categoria Integridade, a qual se refere à aceitação positiva atribuída pelo indivíduo à sua trajetória de vida, avaliando e aceitando os fatos e os limites da vida para poder aceitar a morte. $O$ indivíduo, ao repensar sua vida, tem a sensação de dever cumprido, sentimento de satisfação e dignidade, dividindo suas experiências e sabedoria, foi alicerçada nas subcategorias Aceitação e Valor pela vida.

O Sujeito 22 (65 anos, grande produtor) expressa Aceitação do processo de envelhecimento, reconhecendo que houve perdas físicas no decorrer dos anos, mas houve a compensação pelas experiências adquiridas: "não, eu sou muito tranquilo. Por que eu me considero assim, eu tenho 65 anos, me considero que tenho 30 anos. A gente sente o peso da idade, mas não fica assim pensando porque que eu tenho 60 anos de idade. Então to vivendo a mesma coisa como se tivesse 30 anos. A gente sente que não tem mais aquela força física. Só que hoje a gente tem experiência e não precisa trabalhar mais tanto como quando tinha 30 anos. Então, a experiência supera o cansaço, a dificuldade. A experiência de vida.".

Segundo Erikson (1959), com o passar dos anos, devido às crises que marcam as fases do desenvolvimento, o ego sofre mudanças qualitativas, modificando as vivências, comportamentos e sua personalidade. A oitava fase do desenvolvimento, denominada como Integriade $x$ desespero, é marcada pelas perdas sensoriais, cognitivas e afetivas, aos quais o indivíduo repensa sua trajetória de vida, e, quando há sensação de dever cumprido, satisfação, e dignidade, com intenção de dividir as experiências e sabedorias adquiridas, Erikson (1959) nomeou como Integridade do Ego, aos quais o indivíduo aceita a morte e os limites da vida, assim como também é expresso pelo Sujeito 4 (65 anos, pequeno produtor) (subcategoria Valor pela vida): "A eu não imagino nada né?! Assim, porque envelhecimento assim eu acho mais que é quando a pessoa ta doente não pode fazer nada. Ai parece que ta velha mas assim quando a pessoa tem saúde igual muitos, tem 80 anos ai e trabalha igual uma pessoa novo, porque a idade não representa muita coisa de lado mais ruim. É muito bom desde que a pessoa tem idade avançada mais se ele tem saúde, trabalha anda, vai pra um lado pro outro, ai não faz diferença pra uma pessoa assim muito mais novo".

De acordo com Papalia e Feldman (2013), a sabedoria é a capacidade que o indivíduo tem de fazer um julgamento maduro e justo, possibilitado pelos hábitos estruturados e o conhecimento sobre a vida, sendo o apogeu do crescimento pessoal e desenvolvimento do ego. A sabedoria, permite ao indivíduo aceitar imperfeições em si e no outro, lidar positivamente com as complexidades e incertezas da vida.

A categoria Enfrentamento comtemplou as habilidades, competências, estratégias e recursos individuais e sociais que otimizam o indivíduo em lidar com eventos críticos, desafios, adversidades e situações estressantes, e restabelecer o ajustamento entre a pessoa e o ambiente. Este ajustamento pode ocorrer devido à experiência previa do indivíduo, sucesso neste enfrentamento e experiências de socialização e abrangeu as subcategorias Aceitação e Aceitação e Conformismo.

Dentre as experiências de perdas, ocorrem as influências idiossincrásicas, também conhecidas como não normativas, que, por serem imprevisíveis, demandam mais recursos individuais e sociais para o seu enfrentamento. O Sujeito 19 (80 anos, grande produtor) apresenta em seu discurso as perdas de saúde que limita sua autonomia e o falecimento da esposa que o deixa perdido (subcategoria Aceitação e Conformismo): “Eu estou levando. Não sinto nada. Estou bem, a saúde é boa. Só tenho... Como se diz, só... Só os pneus que são muitos. (risadas). Só os joelhos que são ruim. Os dois foram operados por queda. Os dois por queda. A pessoas cai mais ou menos nessa altura, ainda consegue... Agora, o joeIho sem caminhar. Eu estou assim, como diz o outro, empurrando com a barriga. Os filhos estão aqui, estou com arrendamento, me passa o dinheiro. O guri quase todos os dias vem aqui no sítio. Levando a vida assim... Vai fazer dois anos que a Irene faleceu, aí eu estou meio perdido daí. Não estava preparado para o falecimento dela. [...] E tem a minha cunhada. Que é irmã da Irene. Faz uns dois meses que ela está sem andar. Sempre diz que não tem nada. Não sabe o que que aconteceu. Ela caminha, bem devagarzinho. Vai para cozinha, para sala, para o quarto. Mas está menos ativa". 
O impacto dos eventos não normativos na vida do indivíduo dependerá do grau de exposição individual aos eventos imprevisíveis, pois "têm alta saliência emocional, desafiam o ajustamento preexistente entre a pessoa e o ambiente e conduzem a comportamentos de enfrentamento que têm como objetivo restabelecer o ajustamento entre a pessoa e o ambiente" (Neri, 2013, p. 39).

Estes impactos tendem a ser maiores nas pessoas idosas, devido a diminuição dos recursos e o aumento da frequência de eventos negativos, como doenças, perda de amigos e entes queridos, diminuição do poder aquisitivo, conflitos intrafamiliares, entre outros que possam desestabilizar e independência, autonomia e resiliência do idoso (Diehl, 1999).

Para Reis et al. (2016), o equilíbrio entre as potencialidades e as limitações de cada indivíduo para o enfrentamento das perdas ocorridas durante todo o processo de envelhecimento influenciam na percepção que o indivíduo tem de seu envelhecimento.

Quando o enfrentamento é positivo, o envelhecimento é aceito com naturalidade e êxito, e o indivíduo aproveita suas competências como vantagem para a vida em sociedade (Anjos, 2018; Freitas, 2017; Reis et al., 2016). Dentre as experiências prévias do indivíduo que favorecem o enfretamento, estão as experiências religiosas, nível educacional e características individuais, como saúde, cognição, autoestima, suporte familiar e social, metas e motivações, entre outros (Diehl, 1999).

O Sujeito 17 (87 anos, grande produtor) foca sua atenção das lembranças passadas, como forma de não se preocupar com as mudanças que ocorreram com o envelhecimento: "Não tem nada na cabeça não, não pode pôr, ele leva um empurrão, da um jeito de levantar os amigos que sobrou, conversar, dar atenção a um ou outro, ce vai contar umas piada do tempo que a gente só trabalhou aqui, [...] Então prefiro focar em outras coisas, o pensamento, para não focar no envelhecimento. Não ficar pensando... não é bom ficar pensando muito não, voce tem que pegar e bater duro e faz de conta que não ta acontecendo nada, se for pensar na velhice ai fica velho mais rápido né... Ah nem ideia não tem, porque é uma coisa que veio sem se esperar. Hoje é o dia, amanha é amanha. [...]"

No entanto, a Aceitação, enquanto mecanismo de enfrentamento, pode causar comportamentos hostis por parte dos idosos, tais como isolamento, sentimento de rejeição e depressão, sendo necessário o manejo dos sentimentos e características psicológicas para um melhor envelhecimento. Os Sujeitos da pesquisa que foram categorizados como Aceitação, não expressam sentimentos ou pensamento negativos com relação ao envelhecimento, como o exemplo do Sujeito 20 (66 anos, grande produtor), que está otimista e motivado com seu enveIhecimento (Subcategoria Aceitação): "eu não penso nada... não fico nada aborrecido... quero é ficar mais velho. Quanto mais velho, melhor. ai que vai ser difícil, hein... por que com o envelhecimento eu nunca preocupei. A preocupação é com ficar velho, que ficar velho aí não sabe, não advinha o tempo de quando vai ser. Mas eu pensava de alcança os 60 , já alcancei... perigoso ir pros setenta e pouco, por que a saúde é boa, né?! Eu não penso em nada assim, nunca pensei, penso em não ficar velho. Por isso trabalho, até entrei numa academia. Tem que trabalhar para não envelhecer. Eu quero é ficar firmão até quando der... uns setenta e pouco.",

A categoria Desespero a qual se refere à nostalgia e tristeza vivenciadas pelo indivíduo ao repensar sua vida, aquilo que fez e o que deixou de fazer, desejando que fossem diferentes. O indivíduo manifesta desejo por reviver o passado para modificá-lo e/ou recomeçar a vida, esteve alicerçada nas subcategorias Nostalgia e Desencanto e apreensão.

Para Erikson (1959), a não aceitação da velhice, e o desespero pela finitude, marcam o que denominou como Desespero do Ego, que se manifesta pelo sentimento de desejo e incapacidade de reviver o passado e/ou modificá-lo. O Sujeito 2 (70 anos, pequeno produtor) demonstra em seu discurso a subcategoria Nostalgia: "Eu sinto uma tristeza. Por muita coisa né. Porque a gente quando envelhece, a gente perde muita coisa que a gente tinha no dia-a-dia da gente. Várias coisas.".

O Sujeito 11 (81 anos, pequeno produtor) expressa Desencanto e Apreensão sobre o seu futuro enquanto pessoa idosa: "Aí, eu penso assim, cada dia que passa, né, é só envelhecendo né, porque, voltar atrás você não vai voltar mais. É como se diz, é, por exemplo, se é envelhecimento por causa de doença. Doença a pessoa pega uma doença aí e só vai a cada dia piorando. Hoje em dia você pode tá na mão dos médicos, que as vezes você vai pra lá e sai de lá pior. Como se diz, um abismo chama o outro.". 
Outro fator de desesperança para o envelhecimento está na fragilidade das relações familiares e sociais. Com o envelhecimento ocorre o afastamento progressivo de familiares e grupos sociais, motivados por preconceitos e crenças (Papalia \& Feldman, 2013). Segundo Gunther (2011), as relações sociais e familiares compensam as fragilidades orgânicas e psíquicas acometidas com o envelhecimento, pois nelas há troca de afeto, informações, apoio e sustentação da identidade.

A ausência desse suporte social e familiar exerce efeitos negativos sobre o bem-estar, como expõe o Sujeito 5 (78 anos, pequeno produtor) (subcategoria Desencanto e Apreensão): “[...]Que a pessoa idosa... Pensando na minha maneira de pensar, muitos pensam que eles já tá dando mais trabalho do que alguma coisa que algum lucro, sabe? Então esse é a preocupação da gente com a velhice. É nesse sentido, né? Que você não sabe até quando, até onde você vai... E ao ponto de você ser bem tratado, bem quisto pelos seus. Porque hoje você sabe, hoje em dia quantas pessoas tá no abrigo, né? No asilo. E que tem familiares, né? Então esses são as pessoas, o abandono, né? Quer dizer, certamente na vida, em quanto ele tinha força. Em quanto ele tinha possibilidade de trabalhar, ele ajudou muitas dessas pessoas. Criou. Talvez até os próprios filhos, né? E depois que chegou naquela fase de dar trabalho, de não aguentar fazer mais nada, então ele passou a ser um estorvo na vida desses que ele mesmo cuidou, que ele mesmo (emocionado). [...]".

A categoria Sujeição/Submissão aqui representada pela limitação na autonomia dos indivíduos, ocasionando passividade e dependência física, social, econômica e/ou psicológica, se embasou na subcategoria Dependência.

Segundo Ramos (2003), as condições sociais influenciam na saúde dos indivíduos, uma vez que há maior incidência de doenças crônicas, dependência nas atividades de vida diária e declínio cognitivo em idosos estão nas regiões periféricas e de menor nível socioeconômico. O Sujeito 6 (70 anos, pequeno produtor) expressa a categoria Dependência em seu discurso, devido aos problemas de saúde e a necessidade de ajuda: "Ah, eu acho que pensa "ele não é muito bom, porque...". Depois que "ocê" (você) pensa que a gente já tá ficando "velhinho", as vezes não aguenta nem levantar da cadeirinha, tem que apoiar na mão dos outros. Ai a gente pensa que já tá no final da vida, né? Já não fica muito certo."

A capacidade funcional, conforme pontuam Ribeiro et al. (2013), está relacionada à autonomia do indivíduo e envolve sua integridade física, funções cognitivas, vida emocional e social, exercício de papeis, entre outros. Desta forma, envolve três tipos de atividades: as atividades básicas da vida diária (ABVD) que estão relacionadas ao cuidado pessoal e mobilidade funcional; as atividades instrumentais da vida diária (AIVD) que se relacionam com funções mais complexas, envolvendo gerenciamento pessoal, doméstico e mobilidade na comunidade; e as atividades avançadas da vida diária (AAVD) que estão relacionadas com funções físicas e sociais em ambiente amplificado.

No entanto, Baltes (1996) expressa que a dependência (física, social, econômica e psicológica) pode ser aprendida, pois os comportamentos que a envolvem, muitas vezes são aceitos e reforçados socialmente, pois estão associados a representação social negativa do envelhecimento e perda funcional, e podem prosperar em ambientes que desestimulem a independência, com práticas superprotetoras e infantilizadoras. Os indivíduos que reforçam o comportamento de dependência o fazem atendendo às solicitações de ajuda física ou social, para evitar as manifestações aversivas, culpa ou punição externa.

As funções do comportamento de dependência podem ser para obter ajuda, evitar solidão e/ou preservar recursos físicos e cognitivos, evitando esforços individuais para alcançar níveis mais altos de habilidades e direcionar os recursos economizados para outros que sejam mais importantes para o seu bem-estar.

Por fim, a categoria Agressão, aqui definida como a relação de abuso que acontece tendo por base a diferença de poder entre o agressor e o agredido, por meio do uso intencional de força física ou ameaças que resultem em ferimentos físicos, alterações nas emoções, privações e/ou morte, contemplou a subcategoria Violência/Ageísmo. 
Jesuíno et al. (2017, p. 67) expressam que o preconceito etário, conhecido como "idosismo", "idadismo" ou "ageism" (ageísmo), se sustenta por crenças estereotipadas, preconceitos e discriminação que envolvem o desmerecimento das pessoas mais velhas por serem improdutivas, resistentes à mudança e desmotivadas. O Sujeito 1 (85 anos, pequeno produtor) expressa a subcategoria Violência/ageísmo em seu discurso "Mas o envelhecimento tem que ser a pessoa passar essas coisas assim. Cada dia vai passando uma pessoa novo, se ele passar muita raiva ou for muito castigado ele fica velho dum dia para o outro. Ele fica velho até sem trabalhar, com preocupação. Fica veio (velho)."

Consenza e Malloy-Diniz (2013) atribuem a perda de status e a competitividade dos idosos à modernização e às transformações tecnológicas, uma vez que houve o aumento de idosos fora de posição de prestígio devido à aposentadoria, e as tecnologias desvalorizaram as experiências adquiridas, e afirmam que o ageísmo dificulta o "acesso dos idosos aos serviços, à educação e ao trabalho e pode levar ao abuso, à negligência e ao abandono", intensificando a exclusão social do idoso. Portanto, percebe-se que a participação em sociedade minimiza o isolamento e a discriminação da pessoa idosa (Consenza \& Malloy-Diniz, 2013, p. 444).

Ferreira (2015) explica que quanto mais a sociedade se rende a uma ideologia de juvenilidade e desvalorização e/ou estigmatização do que foge ao modelo, mais se acentuam as discriminações às pessoas idosas. Desta forma, o combate ao idadismo só é possível com a valorização da condição de idoso, incluindo a participação na vida coletiva em suas difersas redes, contatos sociais e acesso à informação diversificada, que assegura a cidadania aos indivíduos mais velhos.

Neri $(2002$, p. 10) expõe que, com relação ao trabaIho, os trabalhadores mais velhos são mais "eficientes em muitas atividades que requerem persistência, precisão, experiência, capacidade de solução de problemas práticos, pontualidade, assiduidade e cuidado", e o ageismo só poderá ser combatido se houver a valorização da condição de idoso, participação na vida coletiva e acesso à informação, que assegura a cidadania aos indivíduos mais velhos.

\section{Considerações finais}

A presente pesquisa buscou analisar os pensamentos e sentimentos sobre envelhecimento para pequenos e grandes produtores rurais do município de Diamantino - MT. Foi possível perceber que o pensamento e sentimento a respeito do envelhecimento, tanto no grupo geral quando separados, é o de enfrentamento, seguido por desespero e integridade. Percebe-se ainda que, nos grupos de pequenos produtores, há o sentimento de submissão dos idosos e situações que envolvem agressão.

Os pensamentos e sentimentos de enfrentamento estão relacionados à percepção otimista de que o tempo passou e que se está vivendo mais, pois os antepassados viviam por menos tempo. Reconhecem o envelhecimento enquanto um processo natural e pré-determinado humano, e identificam os problemas de saúde que são ocasionados pelo envelhecimento, e há comparação da qualidade de vida entre idosos com e sem poder aquisitivo, onde o idoso com poder aquisitivo vive bem, e o sem poder aquisitivo apenas sobrevive enquanto aguarda o fim da vida. No entanto, buscam-se os aspectos positivos da vida, como a prática de atividades físicas e o apoio e convívio com amigos e familiares como forma de passar o tempo com qualidade, tirando o foco dos aspectos negativos do envelhecimento.

Por outro lado, alguns idosos apresentam desespero por causa do envelhecimento. Relatam apenas os aspectos negativos do envelhecimento, como limitações, dependência, prejuízo, incertezas, angústias, ansiedades, abandono, entre outros, e retomam acontecimentos passados, e desejam reviver aqueles acontecimentos, desta forma, não aceitam e não conseguem pensar em alternativas positivas para viver 0 envelhecimento. Reconhecem que alguns idosos são abandonados em asilos por seus familiares, e percebem isso como ingratidão e rejeição.

A percepção oposta à do desespero é manifestada por pensamentos e sentimentos de integridade, manifestada pela aceitação com otimismo do enveIhecimento como um processo natural de ganhos e perdas, limitado pelo tempo. Os idosos manifestam vivências, aprendizados e motivações futuras, sem negar que, durante a vida houve sofrimento e dificuldade. 
O relacionamento e convívio familiar é importante para os pensamentos e sentimentos dos idosos a respeito do envelhecimento. Desta forma, quando o idoso se sente submisso aos membros familiares, o envelhecimento toma conotação negativa, de necessidade e dependência, onde o idoso se sente um "peso" aos familiares. Ainda, em casos mais extremos, porém não raros, o idoso sofre violências físicas ou psicológicas por parte dos integrantes da família.

Durante o processo de execução da pesquisa, mais especificamente na fase das entrevistas algumas dificuldades foram encontradas: participar de pesquisas e fornecer entrevistas não faz parte do cotidiano de muitos idosos, então alguns ficaram receosos em fornecer informações; alguns idosos apresentavam comportamento de evitação ao serem convidados para a pesquisa: inicialmente diziam para ligar em outro momento, e quando havia nova tentativa de ligação, estes não atendiam e não retornavam as ligações. Acredita-se ainda na necessidade de estudos que considerem a diversidade e potencialidades do envelhecimento humano, onde haja espaço para a expressão das identidades sociais no mundo rural e afirmação das novas ruralidades.

\section{Contribuições dos autores}

Tomé AM participou da elaboração e desenvolvimento da pesquisa. Formiga NS participou do desenvolvimento e orientação da pesquisa e correção da versão final.

\section{Conflitos de interesses}

Nenhum conflito financeiro, legal ou político envolvendo terceiros (governo, empresas e fundações privadas, etc.) foi declarado para nenhum aspecto do trabalho submetido (incluindo, mas não se limitando a subvenções e financiamentos, participação em conselho consultivo, desenho de estudo, preparação de manuscrito, análise estatística, etc.).

\section{Referências}

Anjos, P. M. (2018). La psicología en el camino de lo social: um estudio de las representaciones sociales sobre el "envejecer bien" y "envejecer mal" a partir del entorno em la contemporaneidade. [Tese de doutorado não publicada]. Universidad Argentina John F. Kennedy.
Azevedo, M. S. A. (2015). O envelhecimento ativo e a qualidade de vida: uma revisão integrativa. [Dissertação de mestrado, Escola Superior de Enfermagem do Porto]. Repositório comum. https://comum.rcaap.pt/handle/10400.26/10776

Baltes, M. M. (1996). The many faces of dependency in old age. Cambridge University Press.

Banco Nacional de Desenvolvimento Econômico e Social. (2017). Envelhecimento e transição demográfica/Marca-texto. BNDES. https://www.bndes.gov.br/wps/portal/site/home/ conhecimento/noticias/noticia/envelhecimento-transicaodemografica

Bardin, L. (2009). Análise de Conteúdo. Edições 70.

Consenza, R. M., \& Malloy-Diniz, L. F. (2013). Envelhecimento saudável, resiliência cognitiva e qualidade de vida. In L. F. Malloy-Diniz, D. Fuentes, \& R. M. Cosenza (Orgs.), Neuropsicologia do envelhecimento: uma abordagem multidimensional (pp. 428-437). Artmed.

Diehl, M. (1999). Self-development in adulthood and aging: the role of critical life events [Autodesenvolvimento na vida adulta e envelhecimento: o papel dos eventos críticos da vida]. In C. D. Ryff, \& V.W. Marshall. (Eds.), The self and society in aging process (pp.150-183). Springer Publishing Company.

Erikson, E. H. (1959). Childhood and society. Norton.

Ferraz, L., Alves, J., \& Ferreti, F. (2017). A vulnerabilidade ocupacional do idoso no meio rural. Saúde \& Transformação Social/Health \& Social Change, 8(1), 1-14. http://incubadora.periodicos.ufsc.br/index.php/ saudeetransformacao/article/view/4165

Ferreira, P. M. (2015). Envelhecimento e direitos humanos. Conjectura: Filosofia e Educação, 20, 183-197. http:// www.ucs.br/etc/revistas/index.php/conjectura/article/ view/3656/pdf_441

Freitas, L. P. (2017). O Bem-Estar Subjetivo da Pessoa Idosa na Vivência de Uma Opção Religiosa: um Estudo no Estado da Bahia. [Tese de Doutorado, Universidade Autônoma de Lisboa]. Camões - Repositório Institucional da Universidade Autónoma de Lisboa. https://repositorio.ual. pt/handle/11144/3222

Gunther, I. A. (2011). Envelhecimento, Relações Sociais e Ambiente. In D. V. Falcão \& L.F. Araújo (Orgs.), Psicologia do Envelhecimento: relações sociais, bem-estar subjetivo $e$ atuação profissional em contextos diferenciados (pp. 11-25). Alínea. 
Instituto Brasileiro de Geografia e Estatística. (2018). Agência de Notícias: Projeção da População 2018: número de habitantes do país deve parar de crescer em 2047. Agência IBGE Notícias. https://agenciadenoticias.ibge.gov. br/agencia-sala-de-imprensa/2013-agencia-de-noticias/ releases/21837-projecao-da-populacao-2018-numero-dehabitantes-do-pais-deve-parar-de-crescer-em-2047

Jesuíno, J. C., Torres, T. L., Soares, C. C., \& Silva, A. O. (2017). Contribuições para uma gerontologia crítica. In A. O. Silva, \& Z. B. Camargo (Orgs.). Representações sociais do envelhecimento e da saúde (pp. 59-83). Edufrn. https:// repositorio.ufrn.br/jspui/bitstream/123456789/24702/1/ representacoessociais.28.12.pdf

Lei $n^{\circ}$ 6.746, de 10 dezembro de 1979. Altera o disposto nos arts. 49 e 50 da Lei $n^{\circ} 4.504$, de 30 de novembro de 1964 (Estatuto da Terra), e dá outras providências. http://www.planalto. gov.br/ccivil 03/leis/1970-1979/16746.htm

Levinson, D. J. (1978). The seasons of man's life. Knopf.

Levy, B. R., Slade, M. D., Kunkel, S. R., \& Kasl, S. V. (2002), Longevity increased by positive self-perception of aging [Longevidade aumentada pela autopercepção positiva do envelhecimento]. Journal of personality and social psychology, 83(2), 251-270. https://doi.org/10.1037//00223514.83.2.261

Monteleone, T. V., Witter, C., \& Gama, E. F. (2015). Representação Social de Idosos: análise das imagens publicadas no discurso midiático. Estudo interdisciplinar sobre o envelhecimento, 20(3), 921-937. https://seer.ufrgs.br/ RevEnvelhecer/article/view/48330

Moscovici, S. (1981). On social representations [Sobre representações sociais]. In J. P. Forgas (Org.), Social cognition. Perspectives on everyday understanding (pp. 181209). Academic Press.

Muniz, W., \& Souza, D. D. (2018). Reflexões Sobre a Urbanização do Rural e as Contradições Impostas Pela Modernização do Campo. Controle Social e Desenvolvimento Territorial, 4(4), 79-91. https://sistemas.uft.edu.br/periodicos/index. php/csdt/issue/view/306/Artigo\%20.06

Neri, A. L. (2002). Envelhecer bem no trabalho: possibilidades individuais, organizacionais e sociais. A Terceira Idade, 13(24), 7-27. https://www.sescsp.org.br/files/edicao revista/7417fe99-464d-462b-9b15-db35ece4c52e.pdf

Neri, A. L. (2006). Paradigmas contemporâneos sobre o desenvolvimento humano em psicologia e em sociologia. In A. L. Neri (Org.), Desenvolvimento e envelhecimento: perspectivas biológicas, psicológicas e sociológicas (pp. 1138). Papirus.
Neri, A. L. (2013). Conceitos e teorias sobre o envelhecimento. In L. F. Malloy-Diniz, D. Fuentes, \& R. M. Cosenza (Orgs.), Neuropsicologia do envelhecimento: uma abordagem multidimensional (pp.17-42). Artmed.

Organização Mundial de Saúde. (2015). Relatório Mundial de Envelhecimento e Saúde. Organização Mundial de Saúde. https://apps.who.int/iris/bitstream/handle/10665/186468/ WHO_FWC_ALC_15.01_por.pdf?sequence $=6$

Organização das Nações Unidas. (2014). Em 2050, idosos serão dois bilhões de pessoas ou 20\% de toda a população mundial, diz ONU. https://brasil.un.org/pt-br/67772-em-2050-idososserao-dois-bilhoes-de-pessoas-ou-20-de-toda-populacaomundial-diz-onu

Papalia, D. E., \& Feldman, R. D. (2013). Desenvolvimento humano. Artmed.

Parente, M. A. M. P. (Ed.). (2006). Cognição e Envelhecimento. Artmed.

Ramos, L. R. (2003). Fatores determinantes do envelhecimento saudável em idosos residentes em centro urbano: Projeto Epidoso, São Paulo. Cadernos de Saúde Pública, 19(3), 7938. http://dx.doi.org/10.1590/S0102-311X2003000300011

Reis, C. B., Jesus, R. S., Silva, C. S. O., \& Pinho, L. (2016). Condições de saúde de idosos jovens e velhos. Rev Rene, 17(1), 120127. http://www.periodicos.ufc.br/rene/article/view/2632

Santos, A. F., \& Barbosa, G. J. (Orgs.). (2019). Extensão Rural: experiências, pesquisas e sindicalismo (Vol. II). Mídia Gráfica e Editora.

Sticca, M. G., \& Pádua, F. L. A. (2016). Aspectos Laborais na Terceira Idade. In E. R. Freiras, A. J. G. Barbosa, \& C. B. Neufeld (Orgs.), Terapias cognitivo-comportamentais com idosos (pp. 416-428). Sinopsys.

Torres, T. L., Camargo, B. V., Boulsfield, A. B., \& Silva, A. O. (2015). Representações sociais e crenças normativas sobre envelhecimento. Ciência \& Saúde Coletiva, 20(12), 3621-3630. https://dx.doi.org/10.1590/1413812320152012.01042015

Vasconcelos, A. T., \& Jager, M. E. (2016). A percepção de psicólogos sobre o envelhecimento. Psicologia e envelhecimento. Multiciência Online, 15(1), 127-136. http:// www.urisantiago.br/multicienciaonline/adm/upload/v2/ n4/6de47818e9ed00fc37d637f49541cd8b.pdf

Vilela, T. B. (2018). A dependência comportamental aprendida no contexto da relação entre idosos e seus cuidadores informais. [Dissertação de mestrado, Universidade Federal de Minas Gerais]. Repositório UFMG. https://repositorio.ufmg.br/ bitstream/1843/30093/1/ENTREGAR\%20SECRETARIA\%20 DISSERTACAO.pdf 